\title{
ANÁLISE DOS RELATÓRIOS DE EMPRESAS DO SETOR DE SIDERURGIA A PARTIR DAS PERCEPÇÕES DE RESPONSABILIDADE SOCIAL EMPRESARIAL (RSE) PROPOSTAS POR CARROLL
}

\author{
Alessandra Batista ${ }^{1}$ \\ Fabíola Graciele Besen ${ }^{2}$ \\ Valdir Serafim Junior ${ }^{3}$
}

BATISTA, A.; BESEN, F, G.; SERAFIM JUNIOR, V. Análise dos relatórios de empresas do setor de siderurgia a partir das percepções de responsabilidade social empresarial (RSE) proposta por Carroll. Rev. Ciênc. Empres. UNIPAR, Umuarama, v. 21, n. 1, p. 33-61, jan./jun. 2020.

RESUMO: O presente artigo tem como objetivo geral analisar os relatórios anuais e de sustentabilidade das empresas brasileiras do setor siderúrgico, baseados na concepção piramidal (econômica, legal, ética e filantrópica) proposta por Archie Carroll (1979). Tendo como problema de pesquisa: Quais das percepções propostas por Carroll (1979-1991) é evidenciada pelas empresas do setor de siderurgia em seus relatórios contábeis? A metodologia empregada na pesquisa foi construída por meio da análise dos dados contidos nos relatórios anuais e de sustentabilidade do ano de 2016 e 2017 das empresas tratadas no estudo. Utilizou o método bibliográfico e descritivo, guiado por uma análise dedutiva e a pesquisa possui um delineamento com abordagem quantitativa e qualitativa e a amostra foi considerada intencional não probabilística. Os resultados da pesquisa revelaram que todas as empresas estudadas tiveram ao menos uma iniciativa que abrangesse as quatro perspectivas propostas na Teoria de Carroll (1979), se destacando a de caráter ético, que foi a mais explicitada nas formulações de práticas sociais das empresas estudadas.

PALAVRAS-CHAVE: Responsabilidade socioambiental; Ética; Evidenciação; Empresas siderúrgicas.

DOI: $10.25110 /$ receu.v21i1.7209

${ }^{1}$ Graduada em Ciências Contábeis UNIOESTE - Campus de Foz do Iguaçu - Santa Terezinha de Itaipu - PR

${ }^{2}$ Doutoranda em Desenvolvimento Rural Sustentável, Mestre em Desenvolvimento Rural Sustentável, docente no curso de Ciências Contábeis na UNIOESTE - Campus de Foz do Iguaçu ${ }^{3}$ Doutorando em Desenvolvimento Rural Sustentável, Mestre em Desenvolvimento Rural Sustentável, docente no curso de Ciências Contábeis na UNIOESTE - Campus de Foz do Iguaçu 


\title{
ANALYSIS OF STEEL COMPANY REPORTS FROM THE PERCEPTIONS OF CORPORATE SOCIAL RESPONSIBILITY (CSR) AS PROPOSED BY CARROLL
}

\begin{abstract}
This article aims at analyzing the annual and sustainability reports of Brazilian companies in the steel industry based on the archaeological (economic, legal, ethical, and philanthropic) concept proposed by Archie Carroll (1979). It sought to answer the following research problem: Which of the perceptions proposed by Carroll (1979-1991) are evidenced by the steel companies in their financial reports? The methodology used in the research was constructed by analyzing the data contained in the annual and sustainability reports for 2016 and 2017 related to the companies treated in the study. It used a bibliographic and descriptive method guided by a deductive analysis. The research presents a delineation with a quantitative and qualitative approach. The results of the study revealed that all the studied companies had at least one initiative that covered the four perspectives proposed in Carroll's Theory (1979), with emphasis to the ethical one, which was the most explicit in the formulations of social practices of the studied companies.
\end{abstract}

KEYWORDS: Socio-environmental responsibility; Ethics; Disclosure; Steel companies.

\section{ANÁLISIS DE LOS INFORMES DE EMPRESAS DEL SECTOR DE SIDERURGIA A PARTIR DE LAS PERCEPCIONES DE RESPONSABILIDAD SOCIAL EMPRESARIAL (RSE) PROPUESTAS POR CARROLL}

RESUMEN: El presente artículo tiene como objetivo general analizar los informes anuales y de sostenibilidad de las empresas brasileñas del sector siderúrgico, basados en la concepción piramidal (económica, legal, ética y filantrópica) propuesta por Archie Carroll (1979). Teniendo como problema de investigación: ¿cuáles de las percepciones propuestas por Carroll (1979-1991) son evidenciadas por las empresas del sector de siderurgia en sus informes contables? La metodología empleada en la investigación se construyó a través del análisis de los datos contenidos en los informes anuales y de sostenibilidad del año 2016 y 2017 de las empresas tratadas en el estudio. Se utilizó el método bibliográfico y descriptivo, guiado por un análisis deductivo y la investigación posee un delineamiento con abordaje cuantitativo y cualitativo y la muestra se consideró intencional no probabilística. Los resultados de la investigación revelaron que todas las empresas estudiadas tuvieron al menos una iniciativa que abarcase las cuatro perspectivas propuestas en la Teoría de Carroll (1979), destacándose la de carácter ético, que fue la más explicitada en las formulaciones 
de prácticas sociales de las empresas estudiadas.

PALABRAS CLAVE: Responsabilidad socioambiental; Ética; Evidencia; Empresas siderúrgicas.

\section{INTRODUÇÃO}

O termo sustentabilidade, de acordo com Savitz e Weber (2007), surge durante a década de 1980, a partir da conscientização de que os países necessitavam descobrir maneiras de propiciar seu crescimento econômico sem dizimar o meio ambiente ou sacrificar o bem-estar das futuras gerações.

Com o processo de consolidação do pensamento sustentável, onde cada indivíduo possui sua responsabilidade socioambiental no meio em que está inserido, surge o tema Responsabilidade Social Empresarial (RSE), que de acordo com Ethos (2014) abrange uma relação ética e transparente da empresa com os públicos com os quais ela se relaciona.

São diversos os motivadores para as empresas atuarem de maneira socialmente responsável, segundo Tenório (2006), pressões externas (pressões externas à empresa demandados por stakeholders externos), forma instrumental (utilização de vantagens e benefícios de natureza econômica tangível e intangível) e os próprios princípios (valores, missão, cultura organizacional) são alguns desses.

Tachizawa (2002) evidencia que a responsabilidade social empresarial deve ser expressa em valores, condutas e procedimentos que resultem em preservação e melhoria contínua na qualidade de vida da sociedade na visão ética, social e ambiental.

O modo que as empresas demonstram suas iniciativas socioambientais se dá a partir de publicações de balanços sociais ou relatórios de sustentabilidade, segundo Marimon (2012), que são elaborados por meios de diversos indicadores ou parâmetros. Em tais relatórios são demonstrados os projetos, ações e benefícios que a empresa executou dirigidos à sociedade, como explanado por Ethos (2009).

Conforme Azevedo (2006), as empresas continuam tendo como objetivo principal o lucro, porém, passaram a refletir sobre os métodos que amenizam os impactos que suas atividades causam ao ambiente, desenvolvendo ações em prol de seus stakeholders.

Os conceitos intrínsecos e a evolução dos princípios de responsabilidade social empresarial estão presentes na Teoria de Carroll que foi construída em 1979 e aperfeiçoada em 1991, evidenciando que o desempenho empresarial deve ser pautado em quatro elementos essenciais: econômicas, legais, éticas e filantrópicas (CARROLL, 1979-1991). 
O setor siderúrgico foi selecionado para a pesquisa, pois trata-se de uma atividade fundamental ao setor industrial, por fornecer a matéria prima para diversas indústrias, e ser um setor com intensivo consumo de recursos naturais, como minérios, combustíveis fósseis e energia, a aceleração do consumo de recursos do planeta potencializa o seu esgotamento. Assim, as consequências ao meio ambiente, se não controladas, tendem a ser irreversíveis (MARTINEZ et al., 2017).

A partir dessas considerações, formulou-se o seguinte problema de pesquisa: Qual das percepções propostas por Carroll $(1979 ; 1991)$ é evidenciada pelas empresas do setor de siderurgia em seus relatórios contábeis dos anos de 2016 e 2017 ?

Diante disso, a pesquisa tem como objetivo geral analisar os relatórios anuais e de sustentabilidade das empresas do setor siderúrgico nos anos de 2016 e 2017, baseado nas percepções de RSE propostas por Carroll (1979; 1991).

A relevância da pesquisa está pautada em evidenciar se os elementos de responsabilidade social empresarial presentes na proposta por Carroll (1991) se encontram nos relatórios sociais publicados pelas empresas brasileiras do ramo siderúrgico. Além de analisar as práticas socioambientais que as empresas possuem, como já exposto, elas são de suma importância para a sociedade como um todo.

Conforme Buffara (2003), o momento atual do mercado aponta um novo contexto socioeconômico-ambiental e novas responsabilidades devem ser assumidas. No setor siderúrgico, especialmente, por se tratar de um ramo com grandes impactos econômicos, ambientais e sociais pela dimensão de suas atividades e pela importância que exerce na economia brasileira, a análise dessa responsabilidade deve ser ainda mais ampla e complexa.

O presente estudo foi estruturado em cinco seções, incluindo a introdução que compreende a seção 1 . Na seção 2 , o referencial teórico, necessário para a análise de dados. Posteriormente, na seção 3 , descreve-se a metodologia da pesquisa. Na seção 4 apresentam-se os resultados da pesquisa e sua análise. Por fim, na seção 5, as considerações finais são destacadas de acordo com os objetivos pretendidos, seguidas das referências bibliográficas.

\section{REFERENCIAL TEÓRICO}

Neste capítulo, são abordados os conceitos que nortearam o presente estudo: Responsabilidade Social Empresarial (RSE), práticas relacionadas a RSE e as perspectivas propostas por Carroll. 


\subsection{Responsabilidade social empresarial}

A atuação social empresarial vem ganhando crescente destaque no Terceiro Setor, segundo Teodósio (2002), com uma grande divulgação na mídia e debates acadêmicos, principalmente nos de ciências gerenciais. Para exercer livremente suas atividades produtoras de bens e serviços, segundo Lewis (2005), os agentes empresariais devem considerar diversos fatores, entre os principais deles estão: a livre concorrência; defesa dos consumidores, defesa do meio ambiente; redução da desigualdade social; e a oferta de empregos.

Assim as empresas são cada vez mais responsáveis por ações transformadoras em prol de uma sociedade melhor. Nas palavras de Basseto (2010, p. 3) as empresas estão "imbuídas da responsabilidade em desenvolver ações que visem à dignidade humana, sem recorrer a ações que possam prejudicar o seu público, seus clientes, seus fornecedores e a sociedade em que está estabelecida".

\subsubsection{Conceito, objetivo e alcance}

A RSE parte do princípio de que os movimentos corporativos amparem programas envolvendo toda sua cadeia produtiva, onde os indivíduos e/ou grupos dependem dos agentes empresariais para atingirem suas metas e dos quais a empresa necessita para funcionar. Uma valorização social e ambiental passa a ser considerada na gestão, protegendo os recursos, respeitando a diversidade e dissolvendo as desigualdades, criando assim, um cenário melhor às futuras gerações (SCHOMMER; ROCHA; FISHER, 1999; BASSETO, 2010; RIBEIRO, 2005).

A RSE é uma estratégia de sustentabilidade a longo prazo, define Camargo (2007), onde há uma clara preocupação com os impactos sociais e ambientais causados pelas atividades empresariais, ou seja, enquanto a empresa está em busca de resultados, está também explorando maneiras que prejudiquem o mínimo as comunidades em que estão inseridas.

De acordo com Andrade et al. (2009), a RSE está relacionada à conquista do sucesso comercial trilhada por decisões alicerçadas em valores éticos, com respeito as pessoas, a comunidade e ao meio ambiente.

A utilidade da RSE, segundo AECA - Associação Espanhola de Contabilidade e Administração de Empresas (2004) está em atender as deficiências dos variados grupos de interesses, a começar pelas atitudes eficientes e adequadas nesses três aspectos: econômico, social e ambiental.

Dessa forma, nas concepções expostas por Porter e Kramer (2006), ocorre uma relação simbiótica, onde o sucesso da empresa e o da sociedade se fortalecem, culminando em um valor mútuo, de maneira que quanto mais enraizada a questão social com os negócios da empresa, maior a oportunidade 
de impulsionar os recursos e capacidades da empresa, ao mesmo tempo em que beneficia a sociedade.

\subsubsection{Práticas de responsabilidade social empresarial - RSE}

Em nível global, as primeiras práticas sociais foram registradas nos Estados Unidos durante o século XX, e essas práticas criaram a oportunidade de interação da empresa com os colaboradores, proporcionando um bom ambiente de trabalho (AREBOLLA, 2004).

Segundo Ethos (2014), a criação de iniciativas em fomentar sua cadeia de fornecedores e clientes e também incluir os princípios de responsabilidade social em sua gestão são exemplos de práticas de RSE. Em sua concepção, essas práticas possibilitam maior controle dos riscos e oportunidades nos negócios, e possibilita que, tanto a empresa quanto sua cadeia de relações possam empresar estratégias e ferramentas direcionadas ao gerenciamento socialmente responsável.

Nesse sentido, Abreu (2012) também enfatiza que na busca por uma diferenciação no mercado, as empresas assimilam nas práticas de RSE essa possibilidade, representando ganhos à instituição, por valorizar sua imagem no mercado.

Kraemer (2005) aborda que o objetivo não é substituir o órgão público por agentes empresariais, mas as empresas são corresponsáveis pelo desenvolvimento e estruturação de uma sociedade melhor e mais sustentável. Além de que, as organizações têm grandes capacidades de ações na sociedade.

As práticas de RSE, ainda de acordo com Kraemer (2005), estão embasadas nos três pilares do desenvolvimento sustentável: social, ambiental e econômico. Na questão social, além da geração de empregos e circulação de renda na sociedade, a empresa oferece a seus colaboradores os devidos treinamentos e oportunidades igualitárias para homens e mulheres, remunerando-os de forma justa e garantindo-lhes benefícios e direitos.

No âmbito ambiental, a organização produz ações que visam contribuir com a preservação do meio ambiente, como a separação e correta destinação dos resíduos do processo produtivo. Fazendo-se cumprir esses princípios, é possível externalizar impactos positivos na sociedade. Arraigados aos valores, missão e visão da empresa, suas ações irão gerar também resultados financeiros (KRAEMER, 2005).

O Instituto Akatu (2014) fez uma pesquisa e expôs quais são as áreas que a população prefere que sejam realizadas ações de responsabilidade social por parte das empresas no Brasil. O resultado foi saúde, educação, segurança, pobreza e empatados no final, meio ambiente e arte e cultura. 


\subsubsection{Estudos relacionados}

Esta seção do artigo apresenta alguns estudos que contribuíram no desenvolvimento da pesquisa. Com o objetivo de avaliar as práticas de RSE no ambiente interno de duas grandes empresas sediadas em Minas Gerais que eram signatárias da Agenda Global Compact das Nações Unidas, Coelho et al. (2005), buscaram analisar tais práticas no tocante à relação aos avanços e desafios de manter uma postura ética e duradoura com seus colaboradores. As informações foram colhidas através de entrevistas com duzentos e noventa e dois (292) funcionários de janeiro a abril de 2004 que demonstraram a satisfação dos funcionários com as ações das empresas e que, segundo eles, a empresa investia em segurança e saúde de todos, sobretudo no combate ao trabalho infantil.

O estudo realizado pelo pesquisador Milane Filho (2007) objetivou, principalmente, investigar se as empresas que se declaram socialmente responsáveis divulgam informações financeiras específicas de suas ações sociais. Por meio de um estudo de caso com uma amostra formada por 52 empresas, segregando-se em: 34 organizações participantes do ISE e 18 empresas das indústrias de fumo, bebidas alcoólicas e armas. Os resultados encontrados apontaram que, da amostra, $11,8 \%$ entidades componentes do ISE e 72,2\% das organizações vinculadas a externalidades negativas, não divulgam informações financeiras sobre o valor de gastos sociais, gerando dúvidas sobre a existência ou a dimensão dos investimentos à comunidade.

Focando seus esforços a explorar processos organizacionais acerca da RSE, Andrade et al. (2009), realizaram uma pesquisa cujo objetivo foi analisar o balanço social de duas grandes empresas do setor siderúrgico de Minas Gerais, ao longo de dois anos. Os resultados mostram que apesar do discurso das empresas terem como foco principal as razões éticas para investir em RSC, a motivação real é reforço da marca e do posicionamento corporativo.

Realizando um trabalho onde procurou analisar comparativamente as informações socioambientais divulgadas pelas companhias latino-americanas nos seus relatórios, Calixto (2013), abordou uma amostra composta por 226 organizações, no período de 2004 a 2009, segregadas por país, empresa, setor e ano. As conclusões obtidas revelaram que a maioria das companhias de capital aberto na região não disponibiliza informações socioambientais nos seus relatórios anuais ou em relatórios específicos sobre o tema, entretanto, as companhias estabelecidas no Brasil são as que mais destacam o assunto. Ademais, em relação a evolução e à forma de divulgação de informações socioambientais, verificou-se que o relatório anual é o principal canal utilizado pelas companhias para destacar tais informações, seguido do relatório de sustentabilidade, divulgado como parte do relatório anual ou como uma publicação específica. 


\subsection{Perspectivas propostas por Carroll - conceitos e objetivos}

A evolução dos conceitos sobre RSE adquiriram um tipo de percepção sinergética entre elas, se destacando a Teoria de Carroll elaborada em 1979 e aprimorada em 1991.Carroll (1979, p.500), inovou ao afirmar que "a responsabilidade social de uma empresa envolve as expectativas econômicas, legais, éticas e discricionárias que a sociedade tem em determinado período de tempo".

Segundo Macêdo, Gadelha \& Cândido (2014), o modelo proposto por Carroll (1979) se constitui em uma das principais abordagens teóricas da RSE, pois discute o papel e a relevância dos stakeholders a partir das práticas socialmente responsáveis de uma organização, e esse modelo possibilita conhecer ou identificar a percepção de toda a cadeia com que a empresa se relaciona, seus stakeholders, a respeito de sua real atuação social e como essas ações impactam no ambiente interno e externo a organização. Permite ainda, analisar a ação mais adequada de acordo com as necessidades e características dos stakeholders.

\subsubsection{Perspectivas}

Diante do cenário descrito, Carroll (1979) propôs em sua literatura denominada A Three-Dimensional Conceptual Modelof Corporate Performance um modelo tridimensional de performance social, onde procurou refletir diversos conceitos acerca de RSE já disponibilizados anteriormente, promovendo uma nova análise multidimensional desse tema, contribuindo assim, para esclarecer as razões para as ações empresariais. (CARROLL, 1979).

Em 1991, Carroll aprimorou sua definição de RSE a partir de quatro dimensões. Primeiramente, passou a designar o elemento discricionário por filantrópico, sugerindo ainda que essa dimensão fosse responsável por englobar a questão da cidadania corporativa. Segundo, apresentou os quatro componentes do modelo numa pirâmide (conforme figura 1). Deixando claro que, mesmo havendo uma estrutura piramidal, os componentes não podem ser vistos pelas empresas de maneira sequencial, mas sim, de forma simultânea todos os quatro componentes. 
Figura 1: Pirâmide de Responsabilidade social empresarial

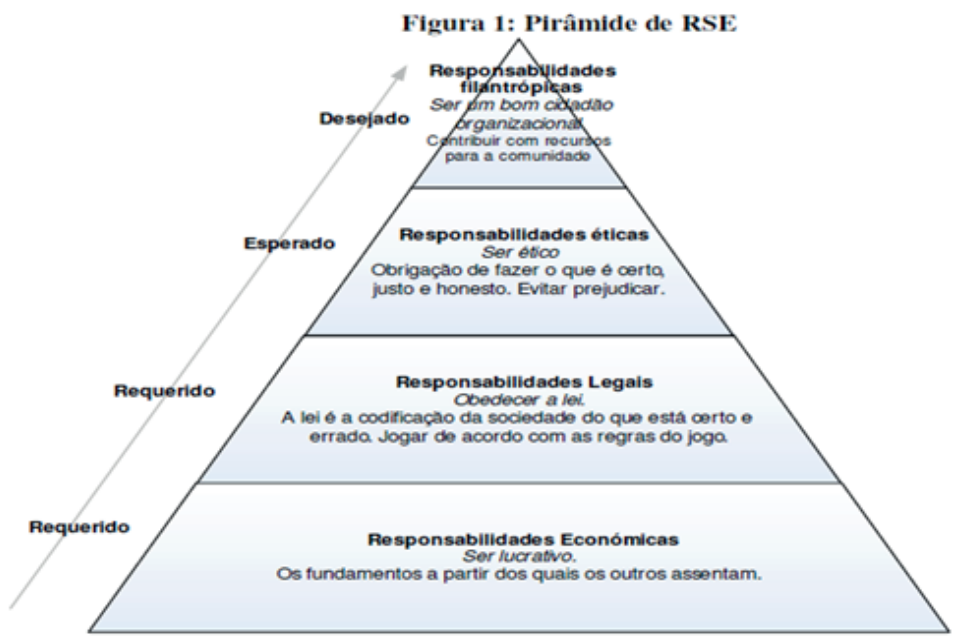

Fonte: Carroll (1991, p. 42)

Na base do desempenho social da empresa, se encontra a responsabilidade econômica, incumbido de produzir bens e serviços que a sociedade necessita e vendê-los de maneira rentável, retratando na empresa, a busca pelo lucro. Posteriormente, a sociedade espera que as empresas cumpram as leis, realizando sua missão econômica nos limites estabelecidos pelo sistema legal, assumindo sua responsabilidade legal perante a sociedade. Espera-se também, que os produtos e serviços ofertados pelas empresas estejam dentro dos padrões de segurança e respeitem as regulamentações ambientais em vigor.

A próxima percepção é a responsabilidade ética, que representa os comportamentos éticos que se espera das empresas, o "fazer justo". As decisões devem ser tomadas considerando suas consequências, os danos que podem ser causados, honrando os direitos dos cidadãos e cumprindo seus deveres éticos. E por fim, a responsabilidade discricionária ou filantrópica representa ações em resposta às expectativas sociais, em que a organização deve atuar como um cidadão ativo e responsável que colabora com melhorias na qualidade de vida da população. Vai além da obrigatoriedade legal, e assume cada vez mais importância estratégica nos negócios.

\subsubsection{Estudos relacionados}

As concepções de Carroll $(1979,1991)$ serviram de base para a elaboração de muitos estudos ao longo do desenvolvimento da RSE. Faria e Leal (2015), desenvolveram uma pesquisa que objetivou estudar as percepções 
de responsabilidade social dos trabalhadores no setor cooperativo português. Buscou identificar se os colaboradores, quando percebem que as cooperativas em que trabalham possuem comportamentos socialmente responsáveis, reagem aumentando o empenho organizacional. Por meio de aplicação de questionário em uma amostra contendo 153 trabalhadores de seis cooperativas portuguesas, se encontraram evidências estatisticamente significativas, de que o nível de empenhamento afetivo é explicado pela conduta ética das empresas, no caso das mulheres e, pelo desempenho econômico e legal das empresas, no caso dos homens.

Campos et al. (2015), realizaram um estudo com o objetivo de analisar as práticas de RSE e as práticas de Gestão de Pessoas nas organizações consideradas modelo em sustentabilidade, RSC e melhores empresas para trabalhar. Através dos Guias Exame de Sustentabilidade e Melhores Empresas para Trabalhar, da Editora Abril S.A., considerando o período de 2006 a 2011. Em relação à dimensão Social/Cultural, observou-se que os resultados expõem uma maior preocupação com o apoio à educação e com o desenvolvimento local. Em relação à dimensão ambiental/ecológica da RSC, constatou-se o predomínio de práticas relacionadas ao uso de materiais recicláveis. Já as práticas de Gestão de Pessoas priorizadas sinalizam ações tradicionais, resultando em menor preocupação com os aspectos sociais, comportamentais e éticos. As organizações investigadas são consideradas modelo em GP e RSC, porém foram evidenciadas lacunas relacionadas à interação da Gestão de Pessoas com as práticas de RSC, dentro das empresas.

Madruga et al. (2017), buscaram analisar em sua pesquisa as dimensões da RSE na concepção piramidal (econômica, legal, ética e discricionária) a partir da concepção dos stakeholders de uma empresa de serviços contábeis do sudoeste do Paraná. Pesquisando clientes, colaboradores e gestor, e utilizando técnicas de observação, análise documental, questionários e entrevistas, foi possível perceber que as dimensões mais visíveis pelas percepções de colaboradores e clientes, por ordem: econômica, ética, legal e, a menos visível, discricionária.

\section{PROCEDIMENTOS METODOLÓGICOS}

Fonseca (2002), afirma que qualquer trabalho científico se inicia com uma pesquisa bibliográfica, que permite ao pesquisador conhecer o que já se estudou sobre o assunto. Dessa forma, a pesquisa define-se como bibliográfica, pois realizou-se uma busca pelos conceitos relevantes ao tema e estudos similares disponíveis em materiais já publicados por outros pesquisadores, que serviram de base ao desenvolvimento da pesquisa.

O estudo caracteriza-se como sendo uma pesquisa descritiva, que 
segundo Churchill e Peter (2000) é o tipo de pesquisa que objetiva conhecer e interpretar a realidade sem nela interferir para modificá-la.

Os métodos são responsáveis pelas vertentes de raciocínios que serão utilizados no desenvolvimento da pesquisa, ou seja, “[...] procedimentos gerais, que norteiam o desenvolvimento das etapas fundamentais de uma pesquisa científica" (ANDRADE, 2001, p. 113-131). Dessa forma, o estudo se caracteriza como dedutivo, que segundo Gil (2008), parte de princípios reconhecidos como verdadeiros e indiscutíveis que possibilitam chegar a conclusões em virtude de sua lógica.

A opção por esse método se justifica pela utilização das informações contidas nos relatórios de sustentabilidade, material esse considerado como verdadeiro para análise e posterior conclusão lógica acerca das ações de responsabilidade social praticadas pelas empresas alvo da pesquisa.

Quanto à abordagem, trata-se de uma pesquisa quali-quanti. A abordagem qualitativa é justificada em razão do objetivo principal do estudo, que busca analisar as ações evidenciadas nos relatórios de sustentabilidade das empresas do setor siderúrgico, baseado nas percepções de RSE propostas por Carroll (1979-1991). A abordagem qualitativa, segundo Alencar (2000), permite reunir uma riqueza de informações sobre determinado assunto, sem haver a necessidade de categorias analíticas previamente estabelecidas.

Referente à abordagem quantitativa, de acordo com Aliaga e Gunderson (2002), pode ser entendida como a "explicação de fenômenos por meio da coleta de dados numéricos que serão analisados por meio de métodos matemáticos (em particular, os estatísticos)". E se justifica por propor evidenciar os valores que as empresas estão destinando à ações sociais e o percentual de ações dentro de cada uma das perspectivas.

A população do presente estudo se compõe das 500 empresas classificadas na última edição da pesquisa "Melhores e Maiores - As 500 maiores empresas do Brasil", realizada pela Revista Exame e divulgada em agosto de 2017.

A amostra considerada intencional não probabilística é composta pelas cinco melhores empresas em vendas líquidas no ramo de siderurgia do Brasil, apresentadas a seguir por ordem de classificação: Arcelor Mittal Brasil, Belo Horizonte, MG; CSN1, Rio de Janeiro, RJ; Usiminas, Belo Horizonte, MG; Gerdau Aços Longos, Rio de Janeiro, RJ; Gerdau Açominas, Ouro Branco, MG.

A coleta de dados foi realizada a partir dos relatórios de administração e sustentabilidade das respectivas empresas, considerando o ano de 2016 e 2017 . E a técnica de análise de conteúdo é a pesquisa documental. Como afirma Chizzotti (2006, p. 98), “o objetivo da análise de conteúdo é compreender criticamente o sentido das comunicações, seu conteúdo manifesto ou latente, as significações explícitas ou ocultas". 


\section{RESULTADOS E DISCUSSÃO}

Na seção 4.1 são apresentados os objetivos das ações sociais praticadas pelas empresas nos anos selecionados como base da pesquisa, comparando cada uma delas com as perspectivas propostas por Carroll $(1979,1991)$ e em qual delas essas perspectivas são mais aplicadas, fazendo uma análise para cada ano e sua correspondente variação.

\subsection{Ações socialmente responsáveis e vínculo com as perspectivas de Carroll}

Os dados foram adquiridos a partir de análises nos relatórios de administração e sustentabilidade das cinco empresas, onde se identificou os objetivos relacionados a cada ação praticada pelas empresas, sua continuidade e o indício de adequação com as perspectivas tratadas na teoria base da pesquisa (Carroll 1979, 1991).

\subsubsection{Arcelor Mittal}

A Arcelor Mittal é considerada a maior produtora de aço da América Latina e mantém ações que englobam desde preocupações relacionadas ao meio ambiente assumindo compromissos e desenvolvendo projetos voltados à preservação da flora e da fauna que estão ao seu entorno, até práticas destinadas à saúde, segurança, desenvolvimento profissional, social e cultural da população (Relatório de Administração - RA, 2016, 2017).

Analisando o Relatório de Sustentabilidade da Arcelor Mittal publicado referente ao ano de 2016, pode-se verificar que ao todo a empresa desenvolveu dez iniciativas voltadas à responsabilidade social empresarial. Delas $30 \%$ apresentaram aspectos legais, $40 \%$ aspectos econômicos, $60 \%$ aspectos éticos e $70 \%$ das iniciativas apresentaram aspectos filantrópicos.

De todas as várias práticas socialmente responsáveis desenvolvidas durante o exercício de 2016, apenas duas delas contemplaram as quatro perspectivas propostas por Carroll.

As ações de responsabilidade ambiental, que foram desenvolvidas pela empresa em 2016 também merecem destaque. Tais ações atendem a perspectiva legal, uma vez que todas as atividades estão devidamente licenciadas e as unidades industriais são $100 \%$ certificadas na ISO 14001. Éticos e legais por terem o cuidado com os indicadores de desempenho relacionados à biodiversidade, água, energia, resíduos e emissões atmosféricas e econômico por ter destinado R $\$ 97,8$ milhões em recursos destinados ao meio ambiente (RA, 2016).

$\mathrm{E}$ as ações desenvolvidas nas áreas da educação e promoção social (Cultura, Esporte e Saúde), que beneficiaram, em 2016, cerca de 288 mil pessoas em 39 municípios, o que justifica seu aspecto ético e filantrópico. Tais ações 
estão alinhadas aos princípios do Pacto Global e às políticas públicas locais, justificando assim seu aspecto legal. Os investimentos destinados a essas ações atingiram R \$ 17 milhões, sendo 68,2\% originados de Leis de Incentivo e 31,8\% de recursos próprios (RA, 2016).

Ações desempenhadas no segmento de Aços Planos teve em seu plano de investimentos ambientais aproximadamente R $\$ 400$ milhões, concluindo os seguintes projetos: reforma e ampliação do sistema de despoeiramento do tratamento de coque, instalação de um novo carro de carregamento na Coqueria e a aplicação automatizada de polímeros na aspersão de pátios. (RA, 2016)

Essa iniciativa contemplou a perspectiva ética, econômica e filantrópica, por estar voltada tanto para a parte interna e externa da empresa, com a preocupação de instalar um sistema de despoeiramento que irá contribuir com as comunidades dos arredores assim como investimentos em maquinários internos, e a perspectiva econômica se justifica com o valor informado do investimento (RA, 2016).

No segmento de Aços Longos, o principal investimento foi destinado à ampliação da capacidade produtiva, com o início da produção do Multibar ${ }^{\circledR}$ barras de alta qualidade voltada para a indústria em geral. Para a fabricação do novo produto, foi instalada uma nova linha industrial, num investimento total de $\mathrm{R} \$ 50$ milhões que transformou a usina numa das mais modernas da empresa no Brasil. Essa ação atendeu apenas a perspectiva ética e econômica, por ter sido desenvolvida voltada para a parte interna da empresa (RA, 2016).

Outra ação marcante realizada pela empresa em 2016 foi a adesão à ONG Transparência Internacional, tornando-a a primeira companhia brasileira a integrar o TI Business Forum. Tal iniciativa atende aos aspectos legais, éticos e filantrópicos, já que esse grupo está voltado a reunir contribuições das corporações à luta contra a corrupção, o que envolve tanto legislações vigentes quanto a colaboração de seu pessoal interno, assim como reflete de maneira positiva na sociedade em geral (RA, 2016).

Uma novidade desenvolvida pela empresa em 2016 que atingiu apenas a perspectiva ética, porém foi muito valiosa para a empresa, foi a utilização de drones nas atividades de riscos. Os drones passaram a ser utilizados na inspeção de estruturas metálicas e chaminés, diminuindo a zero o risco de algum colaborador sofrer um acidente realizando essas verificações (RA, 2016).

Para desenvolver os colaboradores, suas famílias e a comunidade que habita ao seu entorno, a Fundação Arcelor Mittal Brasil iniciou em 2016 o Projeto Vida + Segura. Esse projeto se enquadrou dentro das perspectivas éticas e filantrópicas propostas por Carroll, já que a base da proposta do mesmo é o compartilhamento de informações sobre os riscos à saúde e à segurança em casa, estimulando ações para prevenir acidentes, principalmente com as crianças. (RA, 
2016).

Baseado nos dados divulgados no relatório de sustentabilidade do ano de 2016, a Arcelor Mittal um total de investimentos de cerca de R $\$ 520$ milhões, onde a maior parte desse recurso foi destinado a projetos de manutenção operacional das plantas industriais, controles ambientais, desenvolvimento de novos produtos e melhoria da qualidade (RA, 2016).

Pode-se afirmar que a Arcelor Mittal realizou oito iniciativas sociais identificadas no relatório de sustentabilidade de 2017, onde se verificou que $100 \%$ apresentaram aspectos éticos, $38 \%$ se mostraram vinculadas à perspectiva legal, e $63 \%$ das ações apresentaras aspectos voltados à perspectiva econômica e também em 63\% considerou-se características filantrópicas. (RA, 2017).

Como no ano anterior, duas ações desenvolvidas pela empresa abrangeram as quatro perspectivas propostas por Carroll $(1979,1991)$. O Processo de Despoeiramento foi continuado em 2017, baseado no plano de ação apresentado à Comissão de Meio Ambiente da Assembleia Legislativa do Espírito Santo amparando o aspecto legal da ação e o aspecto econômico foi explicado pela informação de investimento na ordem dos R \$ 101 milhões (RA, 2017).

As perspectivas ética e filantrópica foram identificadas nos claros objetivos da ação, que adotou sistemas de filtros de mangas para a limpeza de gases e resíduos de poeira emitidos pela usina, que é capaz de fazer a retenção física das partículas emitidas. Esse processo deverá reduzir em $18 \%$ as emissões totais de material particulado da empresa, além de evitar a formação de visibilidade da pluma de chaminé da usina. (RA, 2017)

Relacionado também as quatro perspectivas está o Sistema de Gestão Ambiental que busca a sustentabilidade em conformidade com as Políticas de Meio Ambiente. No aspecto econômico, foram investidos cerca de R \$ 404 milhões em sua estratégia de gestão ambiental, destacando-se várias iniciativas como a gestão da água, do ar, dos coprodutos, de energia e de $\mathrm{CO}^{2}$, recebendo também a recertificação pelo programa de Rotulagem Ambiental da Associação Brasileira de Normas Técnicas (ABNT), o que justifica seu aspecto legal (RA, 2017).

Já voltado aos aspectos éticos e filantrópicos, a iniciativa conseguiu criar uma gestão de coprodutos, onde foi possível estimular a economia por meio da premissa da reutilização, comprovando que essa ideia é a mais vantajosa, econômica e ambientalmente, comparado ao descarte ou a reciclagem. Otimizando também a correta destinação desses materiais com o menor impacto ambiental possível e proporcionando ganhos sociais para a região (RA, 2017).

Os projetos que se relacionaram com três das perspectivas, ética, econômica e filantrópica, foram os Projetos Externos e o Programa de 
Responsabilidade Social. A característica econômica dos Projetos Externos pode ser identificada pela informação de investimento de $\mathrm{R} \$ 16,9$ milhões e o caráter ético e filantrópico pela menção de que o desenvolvimento desses projetos externos estão voltados à cultura, à educação, à promoção social, à saúde, à infraestrutura urbana e ao meio ambiente, além de se preocupar com o monitoramento de riscos e impactos socioambientais (RA, 2017).

Enquanto o Programa de Responsabilidade Social mantido pela empresa apoiou e/ou promoveu 14 projetos em 2017, com iniciativas éticas e filantrópicas nas áreas de educação, saúde, cultura e desenvolvimento comunitário, que beneficiaram mais de 25 mil pessoas no ano, com um investimento de $\mathrm{R} \$ 1,08$ milhão nesse período, atendendo as três das quatro perspectivas propostas por Carroll (1979, 1991) (RA, 2017).

A Arcelor Mittal também conta com um Programa de Integridade, que foi instituído em 2007 e se mantêm ativo até os dias atuais. Esse programa atende a duas perspectivas da Teoria de Carroll $(1979,1991)$, a ética e a legal, que se justificam pelo fato do mesmo adotar procedimentos anticorrupção, combate a fraudes, defesa da concorrência, responsabilidade na cadeia de fornecedores, dentre outros, baseados em sua norma de conduta e respeitando os Direitos Humanos garantidos na Constituição de 1988. (RA, 2017).

O Programa de Gestão de Pessoas inclui ações estruturadas de capacitação, treinamento e desenvolvimento (pessoal e profissional) dos colaboradores da empresa, além de manter uma política justa e continuamente atualizada de remuneração e benefícios. Esse programa atende a perspectiva ética, pois, além das características já mencionadas, o mesmo prevê iniciativas de prevenção de acidentes e procedimentos de segurança em todas as áreas (RA, 2017).

Em síntese, na relação com a comunidade a Arcelor Mittal divulgou em seu relatório de sustentabilidade que manteve o investimento social em cerca de R\$ 17 milhões durante o ano de 2017. Tendo suas iniciativas voltadas, principalmente, as áreas de educação, cultura, desenvolvimento social, saúde e esporte, com foco principal para a formação e o estímulo à cidadania (RA, 2017).

A figura abaixo demonstra o comportamento das iniciativas realizadas no decorrer dos dois períodos analisados: 
Figura 2: Iniciativas de RSE por Perspectivas da ArcelorMittal.

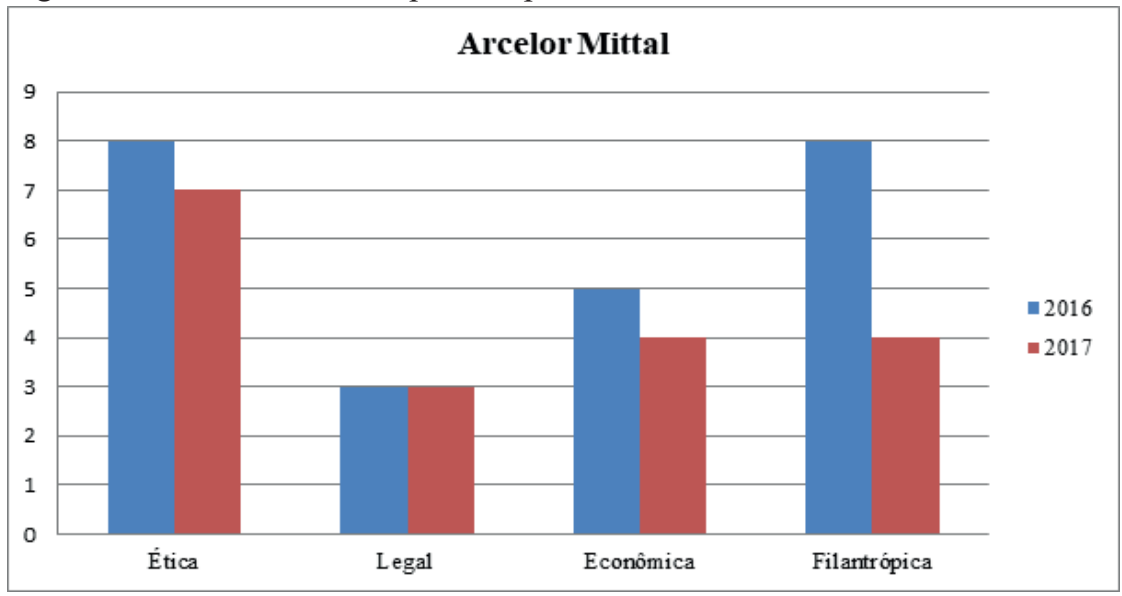

Fonte: Conforme dados da Pesquisa (2018).

Com as informações dispostas dessa maneira, é possível identificar um padrão nas áreas mais investidas em práticas de RSE, onde as perspectivas ética e filantrópica apresentaram maior destaque nos dois períodos, a perspectiva legal manteve a mesma quantidade de ações e a perspectiva econômica embora tenha diminuído, pode ser que a empresa não tenha divulgado as informações econômicas, pois o relatório de sustentabilidade não é obrigatório.

\subsubsection{Usiminas}

A segunda companhia analisada foi a Usiminas, que com 55 anos de operação, se encontra presente em toda a cadeia siderúrgica - da extração do minério, passando pela produção de aço até sua transformação em produtos e bens de capital customizados para o mercado (RA, 2016, 2017).

Em relação às ações socialmente responsáveis colocadas em práticas no ano de 2016 , teve um total de sete iniciativas, onde $14 \%$ se enquadraram no aspecto legal, 29\% tiveram características econômicas, $71 \%$ atuaram no âmbito filantrópico e $86 \%$ apresentaram caráter ético. Apesar de ter desenvolvido várias práticas socialmente responsáveis durante o exercício de 2016, nenhuma delas contemplou as quatro perspectivas propostas por Carroll.

Diversas iniciativas foram postas em prática com foco na participação de colaboradores e sociedade em geral durante o ano de 2016, e com o investimento de aproximadamente R \$ 8,4 milhões foi colocado em ação um total de 63 projetos na área cultural, atendendo mais de 150 mil pessoas que participaram das atrações oferecidas pelo Centro Cultural Usiminas e Teatro Zélia Olguin. 
(RA, 2016)

Essa iniciativa atendeu a três das quatro perspectivas de RSE propostas por Carroll, econômica, ética e filantrópica, devido ao fato de ser voltado tanto para o pessoal interno quanto externo da empresa e por apresentar a quantia investida no mesmo.

Também foram desenvolvidas ações na área da educação por meio do Instituto Cultural Usiminas, onde foram atendidas mais de 34 mil pessoas ao longo de sua programação. As atividades educativas promovidas pelo instituto em públicas e privadas, universidades, grupos portadores de necessidades especiais, creches, grupos de $3^{\mathrm{a}}$ idade e outras instituições sociais, tiveram enquadramento nos aspectos ético e filantrópico da teoria base desse estudo (RA, 2016).

Em 2016, a Fundação São Francisco Xavier, implantou no Hospital Márcio Cunha (HMC) três serviços de grande relevância para a comunidade de Minas Gerais: o Centro de Reabilitação, a Unidade de Cuidados Paliativos e a entrega da ampliação e revitalização do Centro de Terapia Renal Substitutiva (hemodiálise). Essa ação cumpriu com a obrigação filantrópica proposta por Carroll, pois beneficiou a comunidade de maneira geral e indiscriminada (RA, 2016).

Também na área da saúde, após sistematizar seu Sistema de Gestão de Qualidade e cumprir os requisitos exigidos, o COI - Centro de Odontologia Integrada atendendo os aspectos éticos e legais, tornou-se, em 2016, a primeira instituição de assistência odontológica de Minas a receber a certificação ISO 9001. (RA, 2016)

$\mathrm{Na}$ atividade de siderurgia, houve redução das emissões de gases de efeito estufa no período, o que respeitou os quesitos éticos e filantrópicos por estar relacionado a fatores internos e externos a empresa, um bem que favorece a todos. Paralelamente a esta redução, a Usiminas mantém e busca potencializar ações que contribuam para a mitigação das emissões dos gases de efeito estufa (RA, 2016).

Em 2016, a Usiminas investiu em treinamentos para o desenvolvimento de profissionais da área de Siderurgia, abrangendo 3.484 participações e gerando novas oportunidades, atendendo assim as perspectivas ética e filantrópica. Também foram focados os treinamentos em segurança (Normas Regulamentadoras) e qualidade, bem como na educação continuada (Idiomas, Graduação, Pós-Graduação e Mestrado) que englobou 406 participantes (RA, 2016).

Analisando seu relatório de sustentabilidade de 2017, pode-se verificar que a Usiminas desenvolveu oito ações de responsabilidade social, apenas uma a menos do que o ano anterior, mas duas ações contemplaram todas as perspectivas. Sobre o aspecto das perspectivas, de caráter ético esteve presente em 100\% das 
ações, a legal em $63 \%$, enquanto a econômica se apresentou em $50 \%$ das ações desenvolvidas, assim como as de natureza filantrópica (RA, 2017).

Uma das iniciativas da Usiminas que contemplaram todas as perspectivas em 2017 foi seu Sistema de Gestão Ambiental, implementado em 1996 quando se tornou a primeira siderúrgica no Brasil e segunda no mundo a obter a certificação pela Norma ISO 14001, e ao longo de 2017, tem investido mais de R\$ 91 milhões voltados ao meio ambiente (RA, 2017).

A abordagem ética e filantrópica é atendida quando o sistema destina os recursos a programas e ações voltados para a manutenção da eficiência ambiental e redução dos impactos das atividades da empresa no meio ambiente. Além de investir ainda em projetos de educação ambiental em parceria com as comunidades vizinhas às suas operações (RA, 2017).

A Usiminas desenvolveu 46 projetos diversificados em 15 cidades nos estados de Minas Gerais e São Paulo. Foram investidos nesses projetos mais de R\$ 6,3 milhões no ano de 2017, por meio das leis de incentivo federais e municipais como a Lei Estadual de Incentivo a Cultura de Minas Gerais, Lei Federal de Incentivo à Cultura - Lei Rounet, Lei Paulista de Incentivo ao Esporte, entre outras (RA, 2017).

Quanto à perspectiva ética e filantrópica, a política de patrocínios da Usiminas, planejada e executada pelo Instituto Cultural Usiminas, privilegia projetos que promovam a inclusão, a formação e o desenvolvimento humano. Dessa forma, essa é mais uma iniciativa da Usiminas que se relaciona com as quatro perspectivas (RA, 2017).

$\mathrm{O}$ projeto que se relacionou com as perspectivas econômica, ética e filantrópica é a Fundação São Francisco Xavier - FSFX, que é uma entidade filantrópica de direito privado, instituída pela Usiminas em 1969, mantém atuação constante nas áreas de saúde e educação e esforços constantes pela excelência na prestação de serviços, a partir de ações que extrapolam os limites do Vale do Aço (RA, 2017).

Em 2017, foi investido mais de R \$ 9 milhões na reabertura do Hospital de Cubatão (HC) - Dr. Luiz de Camargo da Fonseca e Silva, projeto encabeçado pela FSFX, que contribui para toda a comunidade no envolto do município (RA, 2017).

Nessa mesma linha de ações voltadas ao desenvolvimento social e assistencial se encontra a instituição de ensino Colégio São Francisco Xavier CSFX, que incentiva a conquistar o melhor na vida pessoal e profissional de seus alunos, oferecendo ensino desde Educação Infantil aos cursos de pós-graduação. Sua linha ética e filantrópica está apoiada pelo seu objetivo, que além da missão de educar, incentiva a prática da cidadania (RA, 2017).

Foi a primeira instituição educacional do Brasil a obter a certificação 
ISO 9001 de seu Sistema de Gestão de Qualidade. Portanto, essa iniciativa atende as perspectivas ética, legal e filantrópica (RA, 2017).

A Usiminas também mantém um Programa de Oportunidades Profissionais que incentiva o recrutamento interno, possibilitando aos empregados crescimento profissional, novas oportunidades de carreira e reconhecimento do trabalho desenvolvido, atendendo a expectativa ética. Quanto a perspectiva econômica, foi investido um total de $\mathrm{R} \$ 960$ mil em programas de idiomas (Inglês, Português e Espanhol), graduação, pós-graduação, mestrado, bolsas de estudo e outros (RA, 2017).

Além da carga de treinamentos legais e normativos, a empresa possui um plano estratégico para melhoria de longo prazo e lança mão de ferramentas diversas de modo a estimular a conscientização permanente de empregados próprios e terceiros, como a Hora Segura - que leva as lideranças da companhia para incursões nas áreas operacionais com o objetivo de aprimorar o comportamento seguro - e as Regras de Ouro - regras capitais a serem seguidas diante das tarefas de maior risco, incluindo o Direito de Recusa, garantindo ao empregado a paralisação de atividades sem o devido controle dos riscos (RA, 2017).

Dessa maneira, essas iniciativas atendem as perspectivas éticas e legais por estarem voltadas a maior segurança e confiança do colaborador em seu ambiente de trabalho, estando de acordo com as normas praticadas pela empresa (RA, 2017).

Ofertando assistência médico-hospitalar e odontológica de alta qualidade, o Programa USISAÚDE, é considerado atualmente a maior operadora do Brasil na modalidade filantropia e a sexta maior operadora do estado de Minas Gerais. Está relacionado com as perspectivas ética e filantrópica, por auxiliar os beneficiários a se tornarem os principais agentes da sua saúde, propiciando mudança de hábitos e práticas que levem à melhoria da qualidade de vida e à prevenção de doenças, de forma leve, participativa e resolutiva (RA, 2017).

Proporcionando aos seus colaboradores a oportunidade de melhor planejamento da aposentadoria, a Usiminas conta com a cobertura de previdência complementar, a Previdência Usiminas. Tal iniciativa abrange as perspectivas ética e legal, pois seu modelo de gestão é pautado pela observância aos padrões de governança e transparência, sendo seus recursos garantidores investidos em conformidade com a legislação vigente e políticas de investimentos dos planos de benefícios (RA, 2017).

Com os dados apresentados até aqui é possível realizar uma análise geral dos dados, a partir disso a figura abaixo demonstra o comportamento das iniciativas realizadas no decorrer dos dois períodos analisados: 
Figura 3: Iniciativas de RSE por Perspectivas da Usiminas.

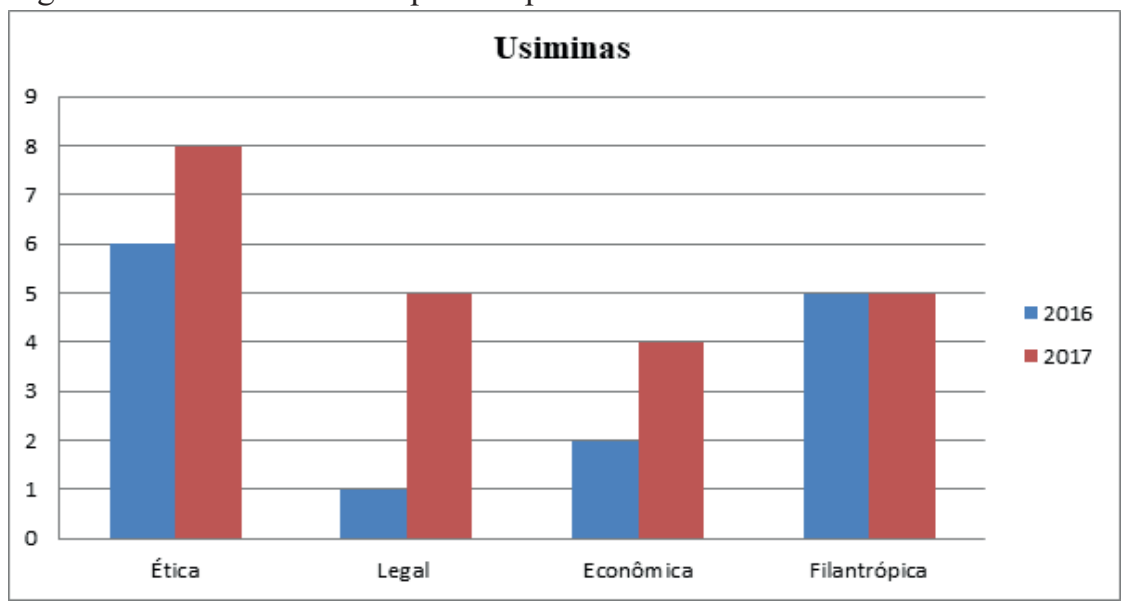

Fonte: Conforme dados da Pesquisa (2018).

É possível identificar que houve aumento no número de ações realizadas nas perspectivas ética, legal e econômica, já a perspectiva filantrópica se manteve com a mesma quantidade de iniciativas nos dois anos analisados.

\subsubsection{Gerdau}

A Gerdau é uma empresa que possui sede no Brasil e presença industrial em mais 12 países - nas Américas, Europa e Ásia. Analisando o relatório de sustentabilidade da Gerdau referente ao ano de 2016, identificou-se oito práticas relacionadas com a responsabilidade social da empresa. O que teve destaque nessa análise é que nenhuma delas destacou a perspectiva legal, em contrapartida, $100 \%$ das ações estavam relacionadas a perspectiva ética da teoria proposta nesse estudo, $63 \%$ atenderam a perspectiva econômica e $75 \%$ a perspectiva filantrópica (RA, 2016, 2017).

As práticas de responsabilidade social da Gerdau são geridas pelo Instituto Gerdau, que é o responsável por determinar as estratégias de atuação social da Companhia e apoiar as operações no desenvolvimento das iniciativas locais de forma a maximizar resultados e otimizar recursos (RA, 2016).

Nesse sentido, teve destaque na área educacional a Technical School, uma escola de ensino profissionalizante mantida pela Gerdau dentro de sua usina em Chimbote, no Peru. A escola prepara jovens em situação de vulnerabilidade social para ingresso no mercado de trabalho, cumprindo um importante papel social nessa comunidade (RA, 2016).

Segundo seu relatório de sustentabilidade, a Gerdau pauta sua atuação 
em prol do desenvolvimento sustentável das regiões onde está inserida, e, por isso, desenvolve inúmeras iniciativas para contribuir para a melhoria da qualidade de vida das comunidades e o desenvolvimento de sua cadeia de negócios. Somente em 2016, R\$ 23 milhões foram destinados a investimentos sociais, com 600 projetos apoiados e ao todo 200 comunidades beneficiadas (RA, 2016).

Com a formação de mais de 1.000 alunos, a escola cumpre com seu papel ético e filantrópico ao estimular a economia local, melhorar a renda familiar, dar oportunidade de os alunos praticarem o que aprenderam e atuarem na otimização de processos produtivos na usina da Gerdau (RA, 2016).

Outra iniciativa que atende aos aspectos éticos e filantrópicos desenvolvida pela empresa é o MMGerdau, o Museu das Minas e do Metal, que contribuiu para a preservação da cultura local. O museu possui um rico e extenso acervo sobre a história da mineração e metalurgia no Brasil, além de intensa programação cultural e educativa, direcionada principalmente para as crianças (RA, 2016).

Também em 2016, a Gerdau investiu R \$ 234 milhões para aprimorar seu sistema de gestão ambiental e suas práticas de ecoeficiência. Tal ação se enquadrou nos quesitos ético e econômico. E como resultado desse processo contínuo de melhoria, a Empresa encerrou o ano com o reaproveitamento de $78 \%$ de seus coprodutos (RA, 2016).

Voltado ao meio ambiente, foram realizadas diversas iniciativas de conscientização para redução do consumo de energia elétrica e busca de eficiência energética nas plantas da Gerdau em 2016. Um exemplo é o projeto Inova Solar, voltado para a redução de custos por meio de geração de energia sustentável (RA, 2016).

Com vistas a Inovação Digital, em 2016 foram investidos R\$ 150 milhões nesse setor, atendendo aos aspectos ético e econômico, pois com o uso de recursos digitais, mobilidade e novas ferramentas foi possível revolucionar o dia a dia da empresa e aprimorar o relacionamento com os colaboradores e clientes (RA, 2016).

A empresa publicou em seu relato anual de 2017 que mantém investimentos nas áreas de meio ambiente, tecnologias e investimentos sociais (RA, 2017).

Atendendo a todas as perspectivas propostas na teoria base desse estudo, os investimentos ambientais chegaram a R \$ 264 milhões. Com ações voltadas à preservação dos ecossistemas no entorno das usinas, onde são mantidos 4 mil hectares de reservas legais ou de preservação permanente, 5 mil hectares de matas conservadas, além de terem sido plantadas mais de 10 mil mudas em 2017 (RA, 2017).

A empresa também possui cerca de cinco mil pessoas capacitadas em 
educação ambiental e aplica nove mil horas de treinamento e capacitação para as mesmas. Além disso, o biocentro criado pela Gerdau possui 48 hectares de áreas preservadas e realiza programas educativos e prêmios que estimulam a atuação dos cidadãos de forma responsável e participativa na preservação dos recursos naturais (RA, 2017).

Além disso, todas as unidades seguem um conjunto de rigorosas práticas alinhadas à norma ISO 14.001, definidas pelo Sistema de Gestão Ambiental (SGA), onde são avaliadas todas as atividades sob o ponto de vista ambiental, desde o recebimento da matéria-prima até a entrega do produto final (RA, 2017).

Relacionado às perspectivas econômica, legal e ética se encontram as outras duas linhas de investimentos realizados pela empresa, Sociais e Tecnológicos. Com cerca de 400 projetos sociais apoiados pelo mundo, os investimentos em 2017 chegaram à casa dos R\$ 19 milhões. (RA, 2017)

Com destaque projetos como o JA Startup, que tem o objetivo de transformar a sala de aula em uma incubadora de startups para desenvolver o mindset empreendedor presente na nova economia. O Projeto TETO também merece destaque por atuar na defesa das pessoas em situações de vulnerabilidade social, apoiando a construção de casas emergenciais em comunidades carentes (RA, 2017).

Desde 2007, a Gerdau é uma das empresas signatárias do Pacto Empresarial Contra a Exploração Sexual de Crianças e Adolescentes nas Rodovias Brasileiras. Nesse sentido, apoia o Programa na Mão Certa, buscando acabar com a exploração sexual de crianças e adolescentes nas estradas brasileiras. Em 2017, quando inaugurou uma nova parceria na província de Santa Fé (Argentina), a Gerdau também contribuiu com a comunidade ao apoiar as obras de ampliação da Escola Técnica Modesto J. Cerrato, contribuindo para o desenvolvimento social dessa população (RA, 2017).

Na busca pela inovação tecnológica, em 2017, a Gerdau inaugurou seu primeiro polo robótico em São José dos Campos (SP). A iniciativa possibilitará a automatização de processos industriais na própria empresa, contribuindo para a produtividade e a segurança no dia a dia das operações (RA, 2017).

Dessa forma, conseguiu alcançar uma redução de custos de cerca de R\$ 30 milhões. Ademais, o espaço conta com uma área para capacitação de colaboradores e comunidade - universitários ou interessados pelo tema, podendo receber até 600 alunos por semana, o que faz com que, cada vez mais, a empresa esteja presente na comunidade (RA, 2017).

Em síntese, o sistema de gestão da Gerdau busca equilibrar os pilares econômico, social e ambiental e a prática da empresa está alinhada ao conceito de economia circular, onde os produtos, ou parte deles, são reutilizados, reparados e reciclados, possibilitando maior eficiência na gestão dos recursos naturais, 
maximizando o bem-estar de toda a sociedade. A figura 4 traz um panorama das perspectivas de 2016 e 2017 :

Figura 4: Iniciativas de RSE por Perspectivas da Gerdau.

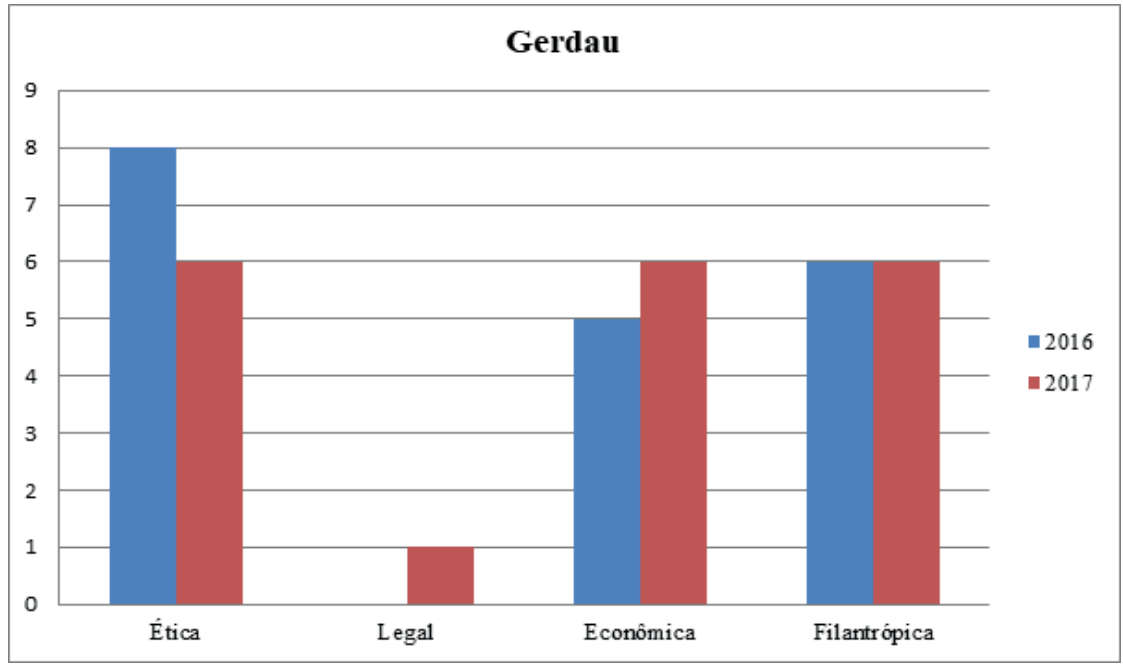

Fonte: Conforme dados da Pesquisa (2018).

Baseado nos dados expostos até aqui é possível analisar a evolução das práticas de RSE desenvolvidas pela Gerdau, como demostrado na figura acima, as iniciativas que apresentaram aumento no número de práticas desenvolvidas foram a legal e a econômica, a filantrópica se manteve com a mesma quantidade e a ética apresentou uma redução, levando em consideração que o relatório de sustentabilidade não é obrigatório às empresas.

\subsubsection{Companhia Siderúrgica Nacional}

A última empresa a ser analisada é a Companhia Siderúrgica Nacional - CSN. Fundada em abril de 1941, foi a primeira produtora integrada de aço plano no Brasil, deixando sua marca no processo de industrialização do país (RA, 2016, 2017).

O grupo está presente em 18 estados brasileiros e mantém atuação na Alemanha e em Portugal. Sendo hoje um dos maiores complexos siderúrgicos integrados do mundo, a CSN se destaca em cinco setores: siderurgia, mineração, logística, cimento e energia (RA, 2016, 2017).

Não foi possível levantar as ações de responsabilidade social desenvolvidas durante o ano de 2016, a única informação de investimento que 
foi encontrada nas informações divulgadas pela empresa foi um investimento na ordem de R \$1.638 milhões, nas áreas de Siderurgia, Mineração, Cimento, Logística e Outros (RA, 2016).

A principal responsável pela atuação social da empresa é a Fundação CSN, criada em 1961, e por meio dela foi possível identificar que em 2017 foi investido em cerca de 15,5 milhões em sua política de apoio a instituições reconhecidas pelo trabalho social que desenvolvem na sociedade, como GRAAC, Museu de Conginhas, Hospital de Barretos, Instituto Albert Einsten, entre outras. (RA, 2017)

A Fundação CSN ainda mantém duas escolas técnicas, a Escola Técnica Pandiá Calógeras (ETPC) e o Centro de Educação Tecnologia (CET), com intuito de preparar estudantes para o mercado de trabalho e também para a faculdade, marcando presença em ações filantrópicas das comunidades que esses projetos abrangem (RA, 2017).

Ainda desenvolvendo ações filantrópicas, a Fundação possui atuação na formação de Jovem Aprendiz, com mais de 10 mil participantes no programa. Por meio de parcerias, fomenta as oportunidades aos jovens em busca pelo primeiro emprego, nos polos em Contagem e Betim (MG) (RA, 2017).

Por fim, relacionado às perspectivas éticas, legais e filantrópicas, a CSN possui sistemas de gerenciamento de qualidade e meio ambiente que são certificados pelas normas ISO 9001 e ISO 14001, respectivamente, o que atende a perspectiva legal das iniciativas. Somadas as políticas de recursos humanos competitivas e uma atuação social permanente, a instituição consegue levar maior desenvolvimento social e econômico as comunidades que se faz presente, além de além de incentivar o aperfeiçoamento cidadão dessa população (RA, 2017).

\section{CONSIDERAÇÕES FINAIS}

$\mathrm{O}$ artigo, em seu objetivo geral buscou identificar e analisar os relatórios anuais e de sustentabilidade das empresas do setor siderúrgico, baseado nas percepções de RSE propostas por Carroll $(1979,1991)$. Os resultados da pesquisa revelaram que todas as empresas estudadas tiveram ao menos uma iniciativa que abrangesse as quatro perspectivas propostas na Teoria de Carroll (1979), se destacando a de caráter ético, que foi a mais explicitada nas formulações de práticas sociais das empresas estudadas.

No geral, o Relatório de Sustentabilidade da Arcelor Mittal publicado referente ao ano de 2016, foi possível verificar que ao todo a empresa desenvolveu dez iniciativas voltadas à responsabilidade social empresarial. Delas $30 \%$ 
apresentaram aspectos legais, $40 \%$ aspectos econômicos, $60 \%$ aspectos éticos e 70\% das iniciativas apresentaram aspectos filantrópicos. Já em 2017 foram identificadas oito iniciativas, onde se verificou que $100 \%$ apresentaram aspectos éticos, 38\% se mostraram vinculadas à perspectiva legal, e $63 \%$ das ações apresentaram aspectos voltados à perspectiva econômica e também em $63 \%$ considerou-se características filantrópicas.

A Usiminas teve um total de sete iniciativas desenvolvidas no ano de 2016 , onde $14 \%$ se enquadraram no aspecto legal, $29 \%$ tiveram características econômicas, $71 \%$ atuaram no âmbito filantrópico e $86 \%$ apresentaram caráter ético. Em 2017 foram oito iniciativas socialmente responsáveis, com destaque às ações de caráter ético que estiveram presentes em 100\% delas, a legal em 63\%, enquanto a econômica se apresentou em $50 \%$ das ações desenvolvidas, assim como as de natureza filantrópicas.

$\mathrm{Na}$ empresa Gerdau referente ao ano de 2016, identificou-se oito práticas relacionadas com a responsabilidade social da empresa, se destacando nessa análise que nenhuma delas atendeu a perspectiva legal, em contrapartida, $100 \%$ das ações estavam relacionadas à perspectiva ética da teoria proposta nesse estudo, $63 \%$ atenderam a perspectiva econômica e $75 \%$ a perspectiva filantrópica. No ano de 2017, 100\% das ações relacionam-se com a perspectiva econômica e ética, $33 \%$ possui fundamentação legal e em $67 \%$ se identificou características filantrópicas.

Na empresa CSN não foi possível fazer essa mesma análise, já que a mesma não possui relatório de sustentabilidade, porém foram identificadas, via website, várias ações socialmente responsáveis na praticadas pela empresa em 18 estados brasileiros, Alemanha e Portugal, onde está presente.

A principal dificuldade ao realizar essa pesquisa foi a falta de padronização na divulgação dos relatórios de sustentabilidade das empresas. Como sugestão de estudos futuros, sugere-se ampliar a pesquisa para os anos anteriores, a fim de verificar se houve uma evolução nos investimentos das empresas, buscando a Responsabilidade Social Empresarial. Outra sugestão seria aplicar a mesma teoria às empresas de outros setores.

\section{REFERÊNCIAS}

ABREU, N. A prática da responsabilidade social nas organizações: Uma análise da Petrobras. Disponível em: http://www.administradores.com.br/ artigos/marketing/a-pratica-da-responsabilidade-social-nas-organizacoes-umaanalise-da-petrobras/66325/. Acesso em: 04 maio 2018.

AECA - Asociación Española de Contabilidad y Administración de Empresas. 
Documentos AECA serie Responsabilidad Social Corporativa. Marco Conceptual de La Responsabilidad Social Corporativa. Documento ${ }^{\circ} 1$. Madrid, España, 2004.

AKATU e ETHOS. Responsabilidade Social das Empresas: percepção do consumidor brasileiro - Pesquisa 2006-2007. Disponível em: https://www. akatu.org.br/wp-content/uploads/2017/04/18-Sum_Pesq_2006_2007.pdf/. Acesso em: 01 maio 2018.

ALENCAR, E. Introdução a metodologia de pesquisa. Lavras: UFLA/ FAEPE, 2000.

ALIAGA, M.; GUNDERSON, B. InteractiveStatistics. Thousand Oaks: Sage, 2002.

ANDRADE, M. A. M.; GOSLING, M.; XAVIER, W. S. Por trás do discurso socialmente responsável da siderurgia mineira. Produção, v. 20, n. 3, p. 418428, jul./set. 2010.

ANDRADE, M. M. Introdução a metodologia do trabalho científico. 4. ed. São Paulo: Atlas, 2001.

ARREBOLA, M. C. Responsabilidade Social: um novo paradigma estratégico de lucratividade e bem-estar social. Revista ANGRAD, v. 5, n. 3, p. 97-114, jul/set. 2004.

AZEVEDO, A. L. V. Indicadores de sustentabilidade empresarial no Brasil: uma avaliação do Relatório do CEBDS. Revista Iberoamericana de Economía Ecológica, v. 5, p. 75-93, 2006. Disponível em: http://www.redibec. org/IVO/rev5_06.pdf. Acesso em: 28 maio 2018.

\section{BASSETTO, L. I. A incorporação da responsabilidade social e} sustentabilidade: um estudo baseado no relatório de gestão 2005 da companhia paranaense de energia - COPEL. Universidade Tecnológica Federal do Paraná, 2010 .

BUFFARA, L. C. B. Desenvolvimento sustentável e responsabilidade social: um estudo de caso no grupo O Boticário. 2003. 145f. Dissertação (Mestrado em Engenharia de Produção) - Universidade Federal de Santa Catarina, Florianópolis, 2003. 
CALIXTO, L. A divulgação de relatórios de sustentabilidade na América Latina: um estudo comparativo. Revista Administração, São Paulo, v. 48, n. 4, p. 828-842, out./dez. 2013.

CAMARGO, A. L. de B. Desenvolvimento sustentável: dimensões e desafios. 3 ed. Campinas, SP: Papirus, 2007.

CAMPOS, S. A. P. de. et al. Práticas de Responsabilidade Social Corporativa e Gestão de Pessoas no Contexto Brasileiro: uma Análise das Empresas Modelo em Sustentabilidade e Melhores para Trabalhar. Revista de Administração de Empresas, UFSM, Santa Maria, v. 8, n. 2, p. 184-201, abr./jun. 2015.

CARROLL, A. B. A three-dimensional conceptual model corporate performance. The academy of Management Review, v. 4, n. 4, p. 497-505, oct. 1979.

. The pyramid of corporate social responsibility: toward the moral management of organizational stakeholders. Business Horizons, 1991.

CHIZZOTTI, A. Pesquisa em ciências humanas e sociais. 5. ed. São Paulo: Cortez, 2006.

CHURCHILL, G. A.; PETER, J. Marketing: criando valor para o cliente. São Paulo: Saraiva, 2000.

COELHO, H. M. Q. et al. Discurso e Prática da Responsabilidade Social: um estudo sobre a gestão do público interno em empresas signatárias do Global Compact. In: XXIX Encontro da associação nacional de pós-graduação e pesquisa em administração. Brasília. Brasília: ANPAD, 2005.

ETHOS. Instituto Ethos de Empresas e Responsabilidade Social. Apresenta os indicadores de responsabilidade social nas empresas. São Paulo, 2009. Disponível em: http://www.ethos.org.br/indicadores/. Acesso em: 25 abr. 2018.

. Empresa associada. São Paulo, 2014. Disponível em: http://www. uniethos.org.br/DesktopDefault.aspx?TabID=3344\&Alias=ethos\&Lang=pt-BR. Acesso em: 25 abr. 2018.

FARIA, J.; LEAL, S. As Percepções de Responsabilidade Social e o Empenhamento Organizacional: um estudo aplicado a cooperativas em Portugal,2015. Disponível em: http://repositorio.ipsantarem.pt/ 
handle/10400.15/84. Acesso em: 07 maio 2018.

FONSECA, J. J. S. Metodologia da pesquisa científica. Ceará: Universidade Estadual do Ceará, 2002.

GIL, A. C. Métodos e técnicas de pesquisa social. 6. ed. São Paulo: Atlas, 2008.

INSTITUTO AÇO BRASIL - IABr. Preliminar Estatístico. Dezembro de 2016.

KRAEMER, M. E. P. RSC: Uma Contribuição das Empresas para o desenvolvimento sustentável. GestioPolis, 2005. Disponível em: https://www. gestiopolis.com/rsc-uma-contribuicao-das-empresas-para-o-desenvolvimentosustentavel/. Acesso em: 25 jul. 2018.

LEWIS, S. B. Responsabilidade social e jurídica da empresa. Reflexões sobre o desenvolvimento sustentável. Agentes e interações sob a ótica multidisciplinar. Petrópolis: Vozes, 2005.

MACÊDO, N. M. M. N.; GADELHA, M. A.; CÂNDIDO, G. A. Apresentação da construção dos parâmetros à aplicação do modelo conceitual tridimensional de performance social de Carroll. Revista de Administração. UFSM, Santa Maria, v. 7, n. 2, p. 230-248, 2014.

MADRUGA, B. P. et al. Responsabilidade Social Empresarial: um estudo de caso à luz da concepção piramidal de Archie Carroll. In: VI Congresso IberoAmericano Investigacion Qualitativa. CIAIQ, 2017. Disponível em: https:// proceedings.ciaiq.org/index.php/ciaiq2017/article/view/1181/1143. Acesso em: 25 jul. 2018.

MARIMON, F. et al. The worldwide diffusion of the global reporting initiative: what is the point? Journal of Cleaner Production, v. 33, p. 32-144, sep. 2012

MARTINEZ, I. V. A. L. et al. Emissão de $\mathrm{CO}_{2}$ : a contribuição da siderurgia brasileira no controle dos gases de efeito estufa. Augusto Guzzo Revista Acadêmica, São Paulo, v. 1, n. 20, p. 111-126, jul./dez. 2017.

PORTER, M. E.; KRAMER, M. Strategy and society: the link between competitive advantage and corporate social responsibility. Harvard Business Review, dec. 2006. 
REVISTA EXAME. Melhores e Maiores: as 500 maiores empresas do Brasil. Disponível em: https://exame.abril.com.br/revista-exame/500-maioresempresas/. Acesso em: 04 maio 2018.

RIBEIRO, A. M. L. Responsabilidade Social Empresarial: percepções e possibilidades. Belo Horizonte, 2005.

SAVITZ, A. W.; WEBER, K. A empresa sustentável: o verdadeiro sucesso é o lucro com responsabilidade social e ambiental. Rio de Janeiro: Elsevier, 2007.

SCHOMMER, P. C.; ROCHA, A. G. P.; FISCHER, T. Cidadania empresarial no Brasil: Três organizações baianas entre o mercado e o terceiro setor. In: XXIII ENCONTRO NACIONAL, 1999, Foz do Iguaçu/PR. Anais... Foz do Iguaçu: Associação nacional dos programas de pós-graduação em Administração (ANPAD), 1999.

TACHIZAWA, T. Gestão ambiental e responsabilidade social: estratégias de negócios focados na realidade brasileira. São Paulo: Atlas, 2002.

TENÓRIO, F. et al. Responsabilidade social empresarial. 2. ed. Rio de Janeiro: Editora FGV, 2006.

TEODÓSIO, A. dos S. O terceiro setor como utopia modernizadora da provisão de bens e serviços sociais: dilemas, armadilhas e perspectivas no cenário brasileiro. 2002. 120 f. Dissertação (Mestrado em Ciências Sociais) Pontifícia Universidade Católica de Minas. Belo Horizonte, 2002.

VERGANA, S. C.; BRANCO, P. D. Empresa humanizada: a organização necessária e possível. Revista de Administração de Empresas, v. 41, n. 2, abr./jun. 2001. 